\title{
Does the early introduction of solids promote obesity?
}

\author{
Brian Symon ${ }^{1,2}$, MD, MBBS, Georgina E Crichton $^{2}$, PhD, Beverly Muhlhausler ${ }^{3}$, PhD
}

\begin{abstract}
Childhood obesity is a major public health challenge across the developed world, and it is vital to understand the modifiable factors that contribute to it. The influence of early-life nutrition on predisposition to later obesity and metabolic disease is now well established. Much research has concentrated on the preventative effects of breastfeeding in relation to childhood obesity risk, but the optimal timing of introducing solid foods has received far less attention. This remains a much-debated and contentious issue, and differing guidelines from international bodies have caused confusion among parents. There is no conclusive evidence from current research that introducing solids before six months of age is associated with an increased risk of obesity in infancy or childhood. Current studies suggest that the most clearly established risk factor for childhood obesity is maternal body mass index. There is a need for continued research in this area.
\end{abstract}

Keywords: childhood obesity, infant solids, review

\section{INTRODUCTION}

Childhood obesity is one of the greatest public health issues globally, with an estimated 42 million children under the age of five years being overweight. ${ }^{(1)}$ Approximately one in four Australian children is overweight or obese. ${ }^{(2)}$ Most of these children remain overweight or obese into adulthood, ${ }^{(3)}$ and are therefore at increased risk for adverse health consequences, such as cardiovascular diseases and diabetes mellitus. ${ }^{(4)}$

Both animal and human epidemiological and clinical studies have provided compelling evidence that the nutritional environment before birth and in early infancy is an important determinant of metabolic health later in life..$^{(5,6)}$ In particular, individuals who are exposed to an inappropriately high or inappropriately low nutrient supply during fetal or early postnatal life have an increased risk of later obesity and diabetes mellitus as children and adults. ${ }^{(5)}$ In this context, there has been considerable interest in establishing nutritional practices for the early infant period that can promote optimal metabolic health in later life.

As the timing of introducing solids is arguably one of the most readily modifiable aspects of infant nutrition, establishing evidence-based guidelines on the optimal timing of introducing solids to achieve later metabolic health has the potential to significantly impact the health of future generations. The World Health Organization (WHO) currently recommends exclusive breastfeeding for six months, followed by the gradual introduction of "nutritionally-adequate and safe complementary foods" in conjunction with the maintenance of breastfeeding for up to two years or beyond. ${ }^{(7)}$ However, the WHO recommendations have been challenged by more recent studies that suggest that the optimal timing of introducing solids is likely to be earlier, at least in relation to the avoidance of allergy. The new data has led to the introduction of recommendations by a number of international health agencies that the optimal timing of introducing solids is between four and six months of age. Indeed, population-based surveys in the United States, Australia and
Denmark have consistently indicated that the large majority of parents are introducing solids before six months, ${ }^{(8-11)}$ with some Australian data suggesting that up to $93 \%$ of infants have been given solids before six months. ${ }^{(11)}$

One of the concerns that have been raised in relation to the early (i.e. before six months) introduction of solids is that this practice increases the risk of the infant going on to become overweight or obese in childhood and adult life. This review will discuss some of the current (published) evidence surrounding the relationship between the timing of introducing solids and later obesity risk, and the research gaps that still exist in this area. We also include a commentary based on the clinical experience of the lead author, including preliminary data from a survey of children in whom solids were introduced well before the current recommended time (many before four months of age).

\section{CURRENT RECOMMENDATIONS}

The optimal timing for introducing solid foods to an infant's diet remains controversial and a topic of considerable interest among health professionals, researchers and the community. The WHO guidelines continue to recommend exclusive breastfeeding for the first six months of life to "achieve optimal growth, development and healt $h^{\prime \prime}{ }^{\left({ }^{(7)}\right.}$ These guidelines clearly define 'exclusive' as meaning that they are fed no other food or drink. The infant feeding guidelines released by the National Health and Medical Research Council of Australia in 2012 recommended that solids be introduced at "around six months of age". ${ }^{(12)}$

The debate around the optimal time to introduce complementary foods has centred largely on the impact that this would have on later allergy risk. It was initially believed that delaying the introduction of specific food types (e.g. nuts, egg and wheat) could reduce the risk of allergic disease later in life. ${ }^{(13)}$ A number of prominent studies have now shown that delaying the introduction of allergenic foods increases the incidence of allergies. ${ }^{(14-16)}$ The Learning Early about Peanut 
Allergy trial conducted in the United Kingdom demonstrated that early introduction (4-11 months) and sustained intake (until 60 months) of peanut protein significantly decreased the risk of peanut allergy in children who were medically defined as being at a high risk of peanut allergy. ${ }^{(17)}$ Peanut avoidance in infancy was also associated with a higher frequency of clinical allergy.

Other infant feeding guidelines from international organisations in the United States and Europe differ from those of the $\mathrm{WHO}$, recommending the introduction of solid foods from the age of four to six months. ${ }^{(18,19)}$ For instance, the European Society for Paediatric Gastroenterology, Hepatology and Nutrition (ESPGHAN) Committee on Nutrition recommends that "complementary feeding (i.e. solid foods and liquids other than breast milk or infant formula and follow-on formula) should not be introduced before 17 weeks and not later than 26 weeks ${ }^{\prime \prime}{ }^{(18)}$ Recommendations from the Australasian Society of Clinical Immunology and Allergy and ESPGHAN state that there is no convincing scientific evidence to support previous advice to avoid or delay the introduction of potentially allergenic foods, such as eggs, peanuts and fish, to prevent allergies. ${ }^{(18,20)}$ The American Academy of Pediatrics recommends no introduction of foods other than breast milk or formula before four months of age, and no introduction of sweetened beverages before six months of age. ${ }^{(21,22)}$ We were unable to find evidence in the published literature of the risks involved if solids are introduced before four months, although this practice is commonly discouraged.

\section{EARLY INTRODUCTION OF SOLIDS AND OBESITY RISK: CURRENT EVIDENCE}

One argument raised by health professionals is that earlier introduction of solids (i.e. before six months) is associated with an increased risk of the child becoming overweight or obese. This argument is based on a number of epidemiological studies, which suggest that infants who are started on solids before the recommended six months have a higher risk of obesity compared to those who commence solids at or after six months of age. ${ }^{(23-26)}$ However, these results are far from universal, with other studies finding no association between the timing of introducing solids and measures of overweight or obesity later in childhood. ${ }^{(27-31)}$ These studies (Table I) represent a small part of this literature.

Three more comprehensive reviews that examined the timing of the introduction of solids and obesity risk were recently conducted. ${ }^{(32-34)}$ Moorcroft et al, ${ }^{(34)}$ who included 24 studies and data from over 34,000 infants/children, concluded that there was no clear association between the age of introduction of solids and obesity. The other two reviews also concluded that there is no clear evidence showing an association between the introduction of complementary feeding between four and six months of age and childhood obesity, although they noted that introducing solids prior to four months may result in an increased risk of children becoming overweight. ${ }^{(32,33)}$ However, this conclusion in the latter two reviews was based on a very small number of studies. There are a number of factors that may contribute to the disparate findings. These include the lack of control for potentially important confounders, small sample sizes resulting in a lack of power, and reliance on retrospective recall for outcome measures, which affects internal validity. Potentially important confounders are not always identified and included in analyses, including method of milk feeding, child's birth weight, sociodemographic factors and important maternal factors such as body mass index (BMI), as well as which foods were introduced (and at what volumes). Also, overweight and obese women are less likely to initiate breastfeeding and, if initiated, will breastfeed for shorter durations than normal-weight women. ${ }^{(35,36)}$ Many studies on infant and child weight have failed to control for maternal BMI in studies that examine the duration of breastfeeding ${ }^{(37-39)}$ or timing of introducing solids. ${ }^{(25,26)}$ Thus, there is currently a lack of robust evidence that the introduction of solids before six months of age increases an individual's subsequent risk of overweight or obesity.

\section{CLINICAL PERSPECTIVE: SOLIDS BEFORE FOUR MONTHS OF AGE}

The lead author of this article encourages the introduction of solid foods into the infant diet (in conjunction with continued breastfeeding, where possible) well before the recommended six months of age, usually by 10-12 weeks. This practice is part of an integrated care plan that has been demonstrated, in a randomised controlled trial, to improve sleep duration in infants and breastfeeding duration in mothers. ${ }^{(40)}$ Despite these positive outcomes, however, there is reluctance on the part of other health professionals to adopt the practice of introducing solids ahead of current recommendations. While the reason for this is unclear, it appears to centre largely on the perceived negative effects on infant health, in particular the risk of early excess nutrition promoting fat deposition and increasing later obesity risk. While this is a legitimate concern in the context of the current obesity epidemic, as outlined above, there is currently limited evidence that this concern is warranted.

In order to investigate this further, we undertook a review of a group of 61 children who had attended the principal author's clinic between 2002 and 2008, and who had commenced solids before four months of age, to examine any association between the timing of solids being introduced and BMI in childhood. We focused specifically on infants with a body weight greater than the 90th percentile at the time of their final clinic appointment (at approximately three months of age), determined using the infant growth charts provided by the United States Centers for Disease Control and Prevention. ${ }^{(41)}$ If excess infant weight gain is associated with heightened risk of obesity later in life, this group of infants may be expected to represent those at the greatest risk of obesity in childhood. The study was approved by the Human Research Ethics Committee of the University of Adelaide, Australia.

Our preliminary findings suggest that the age of introduction of solids (age range 4-28 weeks) was unrelated to the child's BMI percentile or BMI Z-score at follow-up (age range 3-11 years). The only factors that emerged as significant predictors of BMI percentile at follow-up were parental anthropometrics, with 


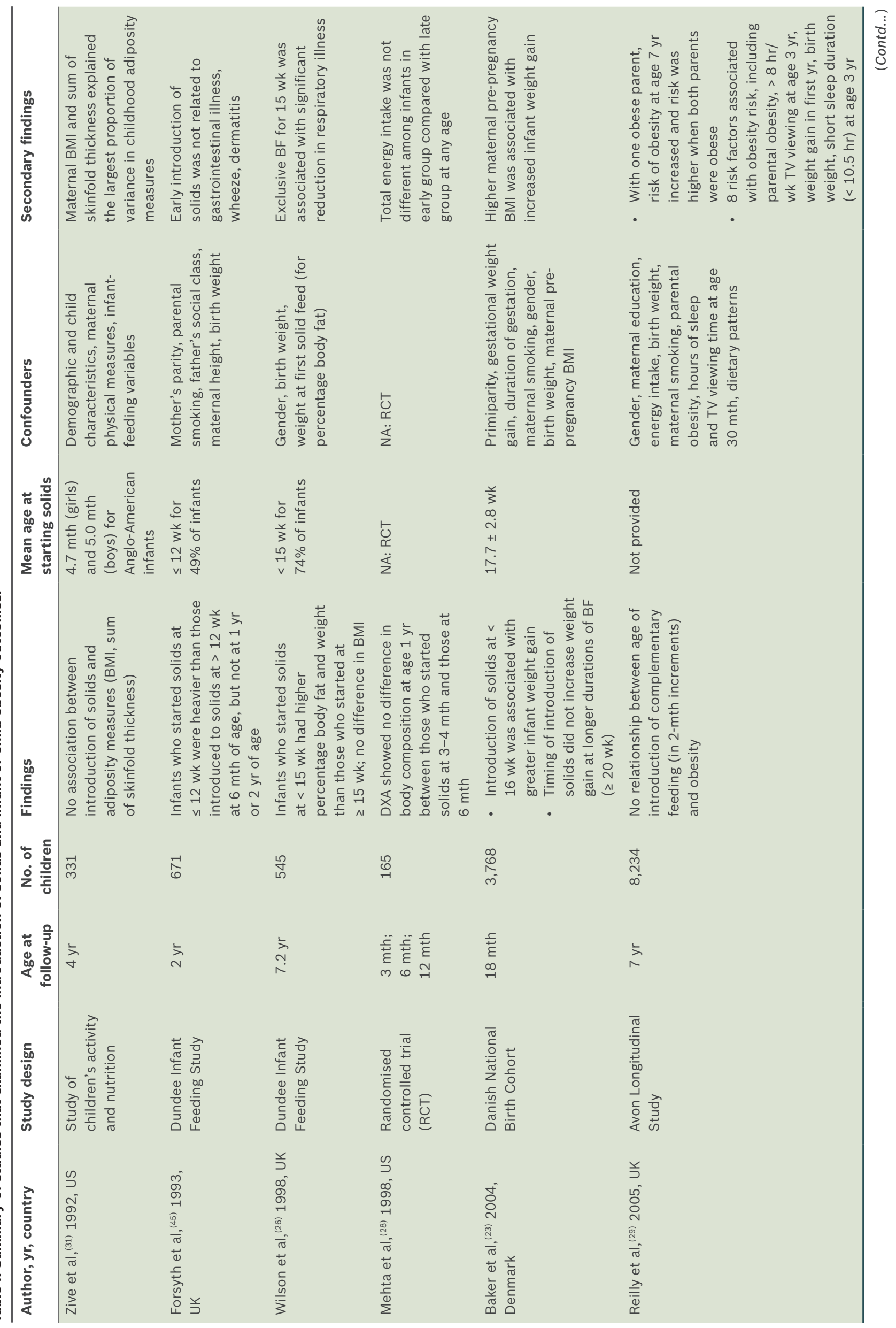




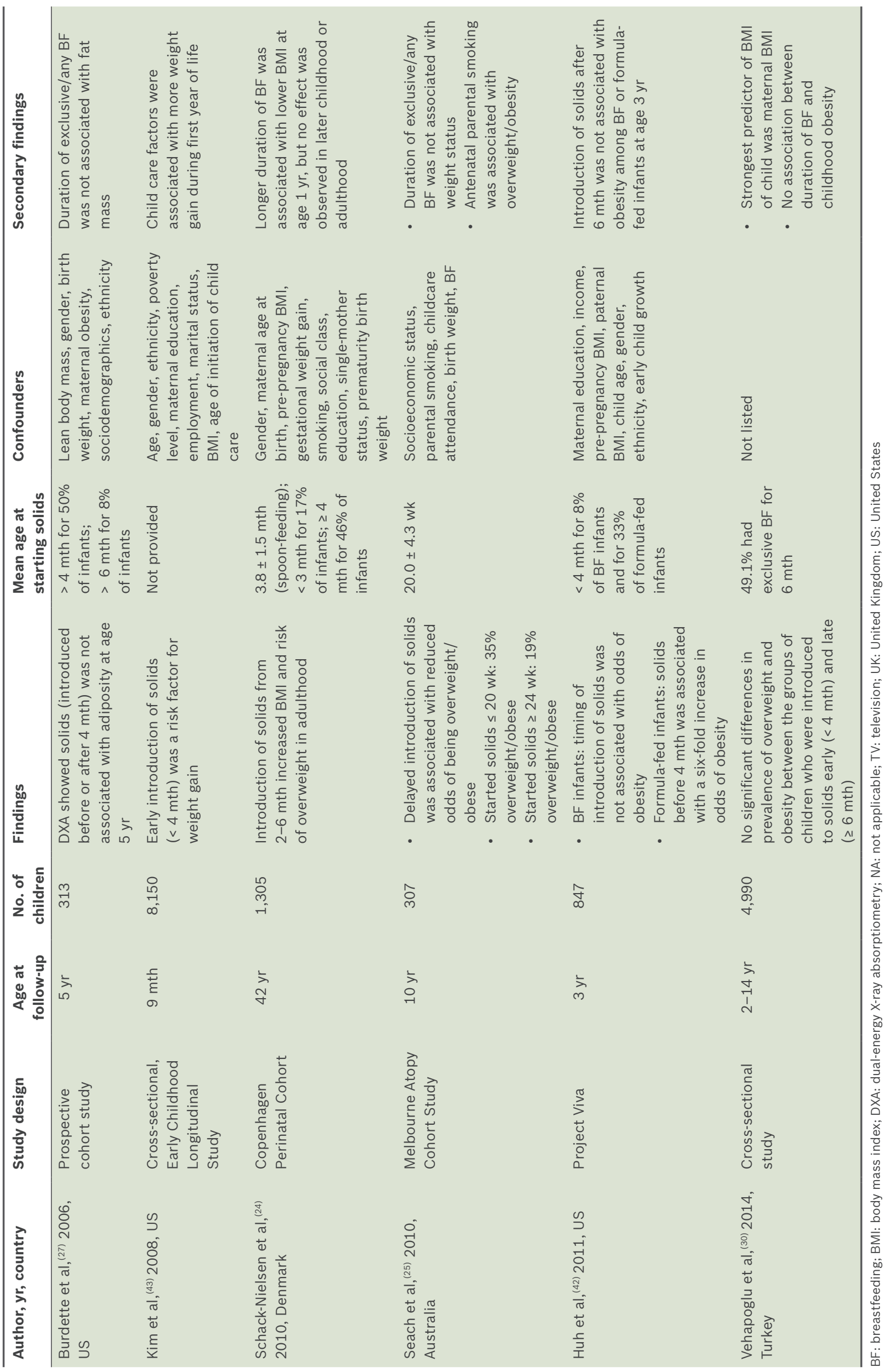


significant positive relationships between both maternal BMI $(r=0.34 ; p=0.009)$ and paternal BMI $(r=0.44 ; p<0.001)$. These predictors remained highly significant in the multivariate model (statistically adjusted for gender, age, birth weight, maternal education, parental smoking and breastfeeding duration; $p<0.0001$ for both maternal and paternal BMI).

\section{TYPES OF SOLIDS INTRODUCED AS FIRST FOODS}

The content of early solids undoubtedly varies in people from different countries, cultures and socioeconomic status. For example, the first foods given in the United States and Australia are usually infant cereal, and pureed fruit and vegetables. The Chinese prefer to give gruel boiled with pork bones, and in Singapore, many parents give rice gruel with powdered anchovy. Unfortunately, very few of the reviewed studies specifically measured or described the type of solid foods that were given as first foods. The exception to this was a study by Schack-Nielsen et $\mathrm{al}^{(24)}$ who reported the risk of overweight at age 42 years according to the age of introduction of spoon-feeding (infant cereal), vegetables, egg, meat and firm food (considered to be soaked bread and biscuits). Other studies stated the types of foods that were considered as 'complementary or solid foods' but did not relate these foods directly to the outcome measure. ${ }^{(27,42,43)}$ While examining the type of foods first introduced, as well as their relative energy values, was not an aim of this review, it must certainly be acknowledged as a relevant factor that is of importance for future research.

\section{CONCLUSION}

The interplay between rate of growth, feeding methods, parental weight status and socioeconomics in determining an individual's risk of becoming overweight or obese is undoubtedly complex. However, there is currently no robust evidence that introducing solids before six months of age has any appreciable impact on the risk of overweight and obesity in childhood. Research now indicates that the early introduction of solids should be promoted for health reasons and not simply to 'feed a hungry baby'. The most compelling evidence for this would appear to be related to allergy prevention. As the prevalence of early introduction of solids is likely to increase as awareness of the allergen protection that it provides grows, it is important to better understand whether there are any potential negative long-term consequences to such a practice.

This review highlights the limited data currently available in this area, and the need for well-designed randomised controlled trials to establish the effects of early introduction of solids on child and adult health, and in particular, metabolic health and future allergy risk. In addition, as noted by recent reviews in the field, ${ }^{(44)}$ there is a need to consider the quality and quantity of foods that are introduced. Clinical studies that prospectively follow up with individuals through infancy and childhood are needed to more fully evaluate the effects of early introduction of solid foods on weight gain and other health outcomes later in life.

\section{ACKNOWLEDGEMENT}

The authors wish to thank Mr Michael Bammann for his assistance with data collection.

\section{REFERENCES}

1. World Health Organization. Childhood overweight and obesity. Available at: http://www.who.int/dietphysicalactivity/childhood/en/. Accessed September 1, 2015

2. Australian Institute of Health and Welfare. Overweight and obesity. Available at: http://www.aihw.gov.au/overweight-and-obesity/. Accessed April 1, 2015.

3. Whitaker RC, Wright JA, Pepe MS, Seidel KD, Dietz WH. Predicting obesity in young adulthood from childhood and parental obesity. N Engl J Med 1997; 337:869-73

4. Dietz WH. Health consequences of obesity in youth: childhood predictors of adult disease. Pediatrics 1998; 101(3 Pt 2):518-25

5. McMillen IC, Adam CL, Mühlhäusler BS. Early origins of obesity: programming the appetite regulatory system. J Physiol 2005; 565(Pt 1):9-17.

6. Muhlhausler BS, Duffield JA, Ozanne SE, et al. The transition from fetal growth restriction to accelerated postnatal growth: a potential role for insulin signalling in skeletal muscle. J Physiol 2009; 587(Pt 17):4199-211.

7. World Health Organization. The World Health Organization's infant feeding recommendation. Available at: http://www.who.int/nutrition/topics/ infantfeeding_recommendation/en/. Accessed April 1, 2015.

8. Clayton HB, Li R, Perrine CG, Scanlon KS. Prevalence and reasons for introducing infants early to solid foods: variations by milk feeding type. Pediatrics 2013; 131:e1108-14.

9. Inoue $M$, Binns CW. Introducing solid foods to infants in the Asia Pacific region. Nutrients 2014; 6:276-88.

10. Kronborg H, Foverskov E, Væth M. Predictors for early introduction of solid food among Danish mothers and infants: an observational study. BMC Pediatr 2014; 14:243.

11. Scott JA, Binns CW, Graham KI, Oddy WH. Predictors of the early introduction of solid foods in infants: results of a cohort study. BMC Pediatr 2009; 9:60.

12. National Health and Medical Research Council, Australia. Infant Feeding Guidelines. Canberra: National Health and Medical Research Council, 2012.

13. Shreffler WG, Radano M. Food allergy and complementary feeding. Nestle Nutr Workshop Ser Pediatr Program 2011; 68:141-9; discussion 150-2.

14. Agostoni C, Shamir R. Can a change in policy of complementary infant feeding reduce the risk for type 1 diabetes and celiac disease? Pediatr Endocrinol Rev 2008; 6:2-4

15. Greer FR, Sicherer SH, Burks AW; American Academy of Pediatrics Committee on Nutrition; American Academy of Pediatrics Section on Allergy and Immunology. Effects of early nutritional interventions on the development of atopic disease in infants and children: the role of maternal dietary restriction, breastfeeding, timing of introduction of complementary foods, and hydrolyzed formulas. Pediatrics 2008; 121:183-91.

16. Prescott SL, Smith P, Tang M, et al. The importance of early complementary feeding in the development of oral tolerance: concerns and controversies. Pediatr Allergy Immunol 2008; 19:375-80.

17. Kent AL. Developmental origins of health and adult disease: what should neonatologists/paediatricians be considering about the long-term health of their patients? J Paediatr Child Health 2012; 48:730-4.

18. Agostoni C, Decsi T, Fewtrell M, et al; ESPGHAN Committee on Nutrition. Complementary feeding: a commentary by the ESPGHAN Committee on Nutrition. J Pediatr Gastroenterol Nutr 2008; 46:99-110.

19. United States Department of Agriculture, Food and Nutrition Service. Infant Nutrition and Feeding. Available at: http://www.nal.usda.gov/wicworks/Topics/ FG/CompletelFG.pdf. Accessed April 1, 2015.

20. Australasian Society of Clinical Immunology and Allergy. How to introduce solid foods to infants. Available at: http://www.allergy.org.au/images/stories/ aer/infobulletins/2010pdf/ASCIA_Infant_Feeding_Advice_2010.pdf. Accessed April 1, 2015.

21. Committee on Nutrition. American Academy of Pediatrics: The use and misuse of fruit juice in pediatrics. Pediatrics 2001; 107:1210-3.

22. Gartner LM, Morton J, Lawrence RA, et al; American Academy of Pediatrics Section on Breastfeeding. Breastfeeding and the use of human milk. Pediatrics 2005; 115:496-506.

23. Baker JL, Michaelsen KF, Rasmussen KM, Sørensen TI. Maternal prepregnant body mass index, duration of breastfeeding, and timing of complementary food introduction are associated with infant weight gain. Am J Clin Nutr 2004; 80:1579-88.

24. Schack-Nielsen L, Sørensen Tla, Mortensen EL, Michaelsen KF. Late introduction of complementary feeding, rather than duration of breastfeeding, may protect against adult overweight. Am J Clin Nutr 2010; 91:619-27.

25. Seach KA, Dharmage SC, Lowe AJ, Dixon JB. Delayed introduction of solid 
feeding reduces child overweight and obesity at 10 years. Int J Obes (Lond) 2010; 34:1475-9.

26. Wilson AC, Forsyth JS, Greene SA, et al. Relation of infant diet to childhood health: seven year follow up of cohort of children in Dundee infant feeding study. BMJ 1998; 316:21-5.

27. Burdette HL, Whitaker RC, Hall WC, Daniels SR. Breastfeeding, introduction of complementary foods, and adiposity at 5 y of age. Am J Clin Nutr 2006; 83:550-8.

28. Mehta KC, Specker BL, Bartholmey S, Giddens J, Ho ML. Trial on timing of introduction to solids and food type on infant growth. Pediatrics 1998; 102(3 Pt 1):569-73.

29. Reilly JJ, Armstrong J, Dorosty AR, et al; Avon Longitudinal Study of Parents and Children Study Team. Early life risk factors for obesity in childhood: cohort study. BMJ 2005; 330:1357.

30. Vehapoglu A, Yazıcı M, Demir AD, et al. Early infant feeding practice and childhood obesity: the relation of breast-feeding and timing of solid food introduction with childhood obesity. J Pediatr Endocrinol Metab 2014; 27:1181-7.

31. Zive MM, McKay H, Frank-Spohrer GC, et al. Infant-feeding practices and adiposity in 4-y-old Anglo- and Mexican-Americans. Am J Clin Nutr 1992 55:1104-8.

32. Daniels L, Mallan KM, Fildes A, Wilson J. The timing of solid introduction in an 'obesogenic' environment: a narrative review of the evidence and methodological issues. Aust N Z J Public Health 2015; 39:366-73.

33. Pearce J, Taylor MA, Langley-Evans SC. Timing of the introduction of complementary feeding and risk of childhood obesity: a systematic review. Int J Obes (Lond) 2013; 37:1295-306.

34. Moorcroft KE, Marshall JL, McCormick FM. Association between timing of introducing solid foods and obesity in infancy and childhood: a systematic review. Matern Child Nutr 2011; 7:3-26.
35. Amir LH, Donath S. A systematic review of maternal obesity and breastfeeding intention, initiation and duration. BMC Pregnancy Childbirth 2007; 7:9.

36. Donath SM, Amir LH. Maternal obesity and initiation and duration of breastfeeding: data from the longitudinal study of Australian children. Matern Child Nutr 2008; 4:163-70.

37. von Kries R, Koletzko B, Sauerwald T, et al. Breast feeding and obesity: cross sectional study. BMJ 1999; 319:147-50.

38. Hediger ML, Overpeck MD, Ruan WJ, Troendle JF. Early infant feeding and growth status of US-born infants and children aged 4-71 mo: analyses from the third National Health and Nutrition Examination Survey, 1988-1994. Am J Clin Nutr 2000; 72:159-67.

39. Armstrong J, Reilly JJ; Child Health Information Team. Breastfeeding and lowering the risk of childhood obesity. Lancet 2002; 359:2003-4.

40. Symon BG, Marley JE, Martin AJ, Norman ER. Effect of a consultation teaching behaviour modification on sleep performance in infants: a randomised controlled trial. Med J Aust 2005; 182:215-8.

41. Kuczmarski RJ, Ogden CL, Guo SS, et al. 2000 CDC Growth Charts for the United States: methods and development. Vital Health Stat 11 2002; (246):1-190.

42. Huh SY, Rifas-Shiman SL, Taveras EM, Oken E, Gillman MW. Timing of solid food introduction and risk of obesity in preschool-aged children. Pediatrics 2011; 127:e544-51.

43. Kim J, Peterson KE. Association of infant child care with infant feeding practices and weight gain among US infants. Arch Pediatr Adolesc Med 2008; 162:627-33.

44. Grote V, Theurich M, Koletzko B. Do complementary feeding practices predict the later risk of obesity? Curr Opin Clin Nutr Metab Care 2012; 15:293-7.

45. Forsyth JS, Ogston SA, Clark A, Florey CD, Howie PW. Relation between early introduction of solid food to infants and their weight and illnesses during the first two years of life. BMJ 1993; 306:1572-6. 